\title{
GESTÃO DA INFORMAÇÃO NO SISTEMA DE PROCESSO JUDICIAL ELETRÔNICO EM UM TRIBUNAL REGIONAL DO TRABALHO
}

\author{
Bárbara Carvalho Diniz ${ }^{1}$ \\ Universidade Federal da Paraíba \\ dinizbarbara6@gmail.com \\ Alzira Karla Araújo da Silva ${ }^{2}$ \\ Universidade Federal da Paraíba \\ alzirakarlaufpb@gmail.com
}

\begin{abstract}
Resumo
Reconhecendo a importância de a informação ser um elemento basilar para o poder judiciário, analisa a gestão da informação no Sistema de Processo Judicial Eletrônico (PJe) do Tribunal Regional do Trabalho (TRT) da 13 Região. Caracteriza-se como pesquisa exploratória-descritiva, do tipo documental e de campo, com abordagem qualiquantitativa. Os dados foram coletados por meio de entrevista semiestruturada e observação sistemática, analisadas a luz da técnica de análise do discurso do sujeito coletivo. Os resultados refletem que o sistema gera agilidade, acessibilidade e melhora no fluxo processual. No entanto, apesar de o sistema gerenciar processos judiciais, considerado documentos arquivísticos, apresenta ausência dos princípios e critérios arquivísticos que podem prejudicar a gestão e o fluxo da informação do sistema. Conclui-se que, embora o sistema PJe traga vantagens, a ausência do cumprimento de requisitos da gestão de informação e da gestão de documentos poderá, futuramente, ocasionar problemas no acesso, uso e preservação das informações.
\end{abstract}

Palavras-chave: Gestão da Informação. Processo Judicial Eletrônico (PJe). Tribunal Regional do Trabalho.

\section{INFORMATION MANAGEMENT IN THE ELECTRONIC JUDICIAL PROCESS SYSTEM IN A REGIONAL REGIONAL LABOR COURT}

\begin{abstract}
Recognizing the importance of information being a basic element for the judiciary, it analyzes the information management in the Electronic Judicial Process System (PJe) of the Regional Labor Court (TRT) of the 13th Region. It is characterized as exploratory-descriptive, documentary and field research, with a qualitative and quantitative approach. Data were collected through semi-structured interviews and systematic observation, analyzed in the light of the collective subject's discourse analysis technique. The results reflect that the system generates agility, accessibility and improves the procedural flow. However, although the system manages legal processes, considered archival documents, it presents an absence of archival principles and criteria, which can harm the management and flow of information in the system. It is concluded that, although the system PJe brings several advantages, the lack of fulfillment of GI requirements and document management may, in the future, cause problems in access, use and preservation of information.
\end{abstract}

Keywords: Information management. Electronic Judicial Process. Regional Regional Labor Court.

\footnotetext{
${ }^{1}$ Mestra em Ciência da Informação pela Universidade Federal da Paraíba (UFPB). Bacharela em Arquivologia pela Universidade Estadual da Paraíba (UEPB).

2 Doutora em Ciência da Informação pela Universidade Federal de Minas Gerais (UFMG). 


\section{INTRODUÇÃO}

Ao longo do tempo, a justiça brasileira tem sido caracterizada como lenta, morosa e burocrática. Dispostos a mudar esta visão e modernizar o poder judiciário, o Conselho Nacional de Justiça (CNJ) criou, em parceria com o Tribunal Federal da $5^{a}$ Região (TRF5), o software do Sistema de Processo Judicial Eletrônico (PJe). O principal objetivo do sistema PJe é oferecer uma solução gratuita aos tribunais de justiça de todo país, independente dos âmbitos judiciários para a tramitação, prática e armazenamento dos processos judiciais eletrônicos (CONSELHO NACIONAL DE JUSTIÇA, 2010, 2016).

O poder judiciário brasileiro encerrou o ano de 2019 com 77,1 milhões de processos em tramitação, esperando uma solução definitiva e apenas 10\% ingressaram como processo físico, ou seja, 90\% dos tribunais já utilizam algum sistema informatizado (CONSELHO NACIONAL DE JUSTIÇA, 2020). O sistema PJe destaca-se como adotado por muitos tribunais do Brasil e o Tribunal Regional do Trabalho $13^{\mathrm{a}}$ Região (TRT), localizado na cidade de João Pessoa/PB, é um dos tribunais a atingir $100 \%$ da virtualização processual no PJe.

O sistema PJe apresenta certo grau de complexidade, não consiste apenas como um sistema de informação que contém dados sobre os processos e partes judiciais, mas é responsável pelo armazenamento, tramitação e práticas processuais executadas pelos técnicos, analistas, magistrados e demais operadores do direito envolvidos no trâmite judicial. Por todos esses fatores, a gestão e o fluxo informacional são essenciais para a organização, acesso, uso e preservação das informações e documentação processual para um julgamento efetivo.

Levando em conta o papel da Gestão da Informação (GI) de gerenciar etapas e o fluxo informacional, assim como de promover o acesso e o uso da informação, destacam-se a aplicabilidade e pertinência da GI no poder judiciário, principalmente no que tange à organização, armazenamento, acesso e uso da informação processual, contribuindo para eficiência e transparência no julgamento de processos. Analisar a gestão e o fluxo informacional no meio digital é de suma importância, em razão de que a informação digital devidamente gerenciada tende a potencializar os recursos informacionais, melhorar fluxo, tramitação, acesso e uso das informações pelos usuários da instituição.

Sabendo que o processo judicial eletrônico veio proporcionar melhor acesso e disponibilidade aos operadores e usuários da justiça e que a análise da gestão da informação do sistema PJe se faz necessária para propor um modelo adequado, visando a eficiência, disponibilidade e acesso à informação processual, apresenta-se a seguinte questão problema: Como acontece a gestão da informação no sistema PJe do TRT $13^{\mathrm{a}}$ Região? Outras questões 
relevantes são: o fato de os processos judiciais estarem em meio eletrônico tem melhorado sua gestão e tramitação? Existem barreiras e/ou fatores facilitadores no sistema?

O objetivo geral do estudo consistiu em analisar a gestão da informação no sistema PJe do TRT $13^{a}$ Região. Para tanto, caracterizou-se o perfil dos usuários (técnicos e analistas judiciários); identificou-se o processo de gestão da informação, os fatores facilitadores e as barreiras que auxiliam o fluxo e a tramitação de informação nesse processo de GI no TRT 13 Região e mapearam-se as necessidades de informação dos técnicos e analistas judiciários das 13 varas do TRT $13^{\mathrm{a}}$ Região.

Como principal justificativa para o estudo apresenta-se a de cunho social pois é missão do poder judiciário realizar justiça e promover a democracia. Diante disso, o gerenciamento das informações e processos judiciais eletrônicos tem devida importância, pois estes apresentam o registro da ação judicial, reunindo provas e atos jurídicos para a resolução de conflitos. Tal pesquisa contribui, portanto, para apresentar elementos que fundamentam uma gestão e fluxo informacional do sistema PJe mais eficiente e eficaz, colaborando para a organização, armazenamento, disponibilidade e preservação das informações e documentos presentes no sistema.

\section{GESTÃO DA INFORMAÇÃO}

É indispensável entender como as informações são gerenciadas e quais são necessárias para o funcionamento e progresso das organizações, sejam elas públicas ou privadas. Em relação ao surgimento da GI, Barbosa (2008) disserta que suas origens modernas estão presentes na obra "Traité de documantation" de Paul Otlet, que mesmo publicada em 1934, já continha aspectos do que se conhece hoje por gerenciamento dos recursos informacionais.

O gerenciamento moderno de informações tem início na revolução do controle dos negócios, no século XX. Algumas mudanças ocorridas por este modelo de gerenciamento modificou a administração dos arquivos até a década de 1970, a mudança de perspectiva sobre o significado de informação pelos profissionais da área, e uma noção mais ampla do significado de Administração de Recursos Informacionais (ARI) (DAVENPORT, 1998).

A GI, de acordo com Grácio (2012, p. 29), perpassa pela coleta, tratamento e armazenamento da informação, buscando o uso da informação a partir de produtos e serviços. Assim, gere informações registradas, produzidas e recebidas em qualquer formato e suporte utilizado para seu armazenamento. Suas atividades iniciam, portanto, no recebimento/coleta de 
informações, passando por tratamento, a exemplo da classificação, descrição e atribuição de acesso, sendo armazenada e, posteriormente, acessada, compartilhada e utilizada.

Em outra perspectiva a gestão da informação é uma associação integrada de ações que buscam detectar desde as necessidades informacionais dos usuários, a mobilidade dos fluxos informacionais em diferentes departamentos da organização, tal qual procedimentos como recebimento, filtragem, análise, organização, armazenamento e compartilhamento da informação (VALENTIM et al., 2008).

Outras áreas do conhecimento contribuem para essa gerência do ciclo informacional, como a Arquivologia nos estudos sobre gestão de documentos arquivísticos. Lima e Duarte (2016) evidenciam que a interdisciplinaridade entre gestão de documentos e GI é necessária para firmar uma política organizacional integrada, que ofereça subsídios e qualifique as atividades de produção, acesso e uso da informação.

Quadro 1 - Modelos para análise da Gestão da Informação no Sistema PJe

\begin{tabular}{|c|c|c|c|c|}
\hline $\begin{array}{c}\text { MODELO DE } \\
\text { McGEE E PRUSAK } \\
(1994)\end{array}$ & $\begin{array}{l}\text { MODELO DE } \\
\text { DAVENPORT } \\
\quad(1998) \\
\end{array}$ & $\begin{array}{l}\text { MODELO DE } \\
\text { CHOO (2003) }\end{array}$ & $\begin{array}{c}\text { MODELO DE SOUZA } \\
\text { E DUARTE }(2011)\end{array}$ & $\begin{array}{l}\text { MODELO DE BEAL } \\
(2012)\end{array}$ \\
\hline $\begin{array}{l}\text { Identificação de } \\
\text { necessidade e } \\
\text { requisitos de } \\
\text { informação } \\
\end{array}$ & $\begin{array}{l}\text { Determinação de } \\
\text { exigências de } \\
\text { informação }\end{array}$ & $\begin{array}{l}\text { Necessidade da } \\
\text { informação }\end{array}$ & $\begin{array}{l}\text { Determinação das } \\
\text { necessidades de } \\
\text { informação }\end{array}$ & $\begin{array}{l}\text { Identificação de } \\
\text { necessidades e } \\
\text { requisitos de } \\
\text { informação } \\
\end{array}$ \\
\hline $\begin{array}{l}\text { Coleta/entrada de } \\
\text { informações }\end{array}$ & $\begin{array}{l}\text { Obtenção da } \\
\text { informação }\end{array}$ & $\begin{array}{c}\text { Busca da } \\
\text { informação }\end{array}$ & $\begin{array}{c}\text { Busca, coleta e análise } \\
\text { da informação }\end{array}$ & $\begin{array}{l}\text { Obtenção de } \\
\text { informação }\end{array}$ \\
\hline $\begin{array}{l}\text { Classificação, } \\
\text { armazenamento, } \\
\text { tratamento e } \\
\text { apresentação da } \\
\text { informação }\end{array}$ & $\begin{array}{l}\text { Distribuição da } \\
\text { informação }\end{array}$ & Uso da informação & Seleção da informação & $\begin{array}{l}\text { Tratamento da } \\
\text { informação }\end{array}$ \\
\hline $\begin{array}{l}\text { Desenvolvimento de } \\
\text { produtos e serviços de } \\
\text { informação }\end{array}$ & $\begin{array}{l}\text { Utilização da } \\
\text { informação }\end{array}$ & & $\begin{array}{l}\text { Organização, } \\
\text { armazenamento e } \\
\text { recuperação da } \\
\text { informação } \\
\end{array}$ & $\begin{array}{l}\text { Distribuição da } \\
\text { informação }\end{array}$ \\
\hline $\begin{array}{l}\text { Distribuição e } \\
\text { disseminação da } \\
\text { informação }\end{array}$ & & & $\begin{array}{c}\text { Desenvolvimento de } \\
\text { produtos e serviços de } \\
\text { informação }\end{array}$ & Uso da informação \\
\hline \multirow[t]{2}{*}{$\begin{array}{l}\text { Análise e uso da } \\
\text { informação }\end{array}$} & & & $\begin{array}{c}\text { Distribuição, } \\
\text { compartilhamento e } \\
\text { disseminação da } \\
\text { informação }\end{array}$ & $\begin{array}{l}\text { Armazenamento da } \\
\text { informação }\end{array}$ \\
\hline & & & Uso da informação & $\begin{array}{l}\text { Descarte da } \\
\text { informação }\end{array}$ \\
\hline
\end{tabular}

Fonte: Adaptado de McGee e Prusak (1994), Davenport (1998), Choo (2003), Souza e Duarte (2011) e Beal (2012).

Em relação aos modelos que descrevem e operacionalizam as etapas da GI, neste estudo foram explorados e utilizados cinco (5) para analisar a gestão da informação no sistema PJe. 


\section{ARTIGO}

INOVAÇÃo

Três desses modelos são clássicos para os estudos da GI, como o de McGee e Prusak (1994), Davenport (1998) e Choo (2003). Já os outros dois são mais recentes e apresentam uma visão complementar aos anteriores, são o de Souza e Duarte (2011) e Beal (2012). O Quadro 1 representa as etapas de GI nesses modelos que foram utilizados para analisar a GI no sistema PJe do TRT $13^{a}$ Região.

Os modelos apresentados descrevem as etapas que a informação perpassa nos fluxos institucionais. Tais modelos, de alguma forma, buscam de forma lógica a consecução de atividades que facilitem o acesso, o compartilhamento e o uso eficaz das informações organizacionais para serem utilizadas pelos usuários do nível operacional ao nível gerencial.

\section{SISTEMA DE PROCESSO JUDICIAL ELETRÔNICO}

A história do sistema PJe tem sua base na lei 11.419/2006 que trata sobre a regulamentação do processo judicial em meio eletrônico, autorizando o uso de softwares específicos para a criação, tramitação e armazenamento de processos judiciais no âmbito digital. Tendo em vista a nova realidade que buscava a informatização do processo judicial, o CNJ criou, no ano de 2009, em parceria com o Tribunal Regional Federal da $5^{\text {a }}$ Região, o software do Sistema de Processo Judicial Eletrônico (PJe) que:

[...] caracteriza-se pela proposição da prática de atos jurídicos e acompanhamento do trâmite processual de forma padronizada, mas considerando características inerentes a cada ramo da Justiça. Objetiva a conversão de esforços para a adoção de solução única e gratuita aos tribunais, atenta à racionalização de gastos com elaboração ou aquisição de softwares, permitindo o emprego de recursos financeiros e de pessoal em atividades dirigidas à missão do Poder Judiciário. O sistema funciona inteiramente pela Internet, possui distribuição gratuita aos órgãos do Judiciário, utiliza soluções tecnológicas open source e tem como diretriz a utilização de criptografia nos registros dos atos processuais, por intermédio de certificação digital no padrão ICP-Brasil, de modo a garantir a integridade e a segurança das informações (CONSELHO NACIONAL DE JUSTIÇA, 2016, p. 8).

Antes do software PJe, o tribunal era responsável pela criação ou compra de um software que gerenciasse e tramitasse os processos digitalmente. Cada tribunal tinha seu padrão, características e particularidades, não existindo padronização no fluxo e tramitação processual em relação aos outros tribunais.

Visando a economia dos recursos financeiros com gastos em informatização dos processos, bem como a padronização do processo judicial eletrônico, foi criado o sistema PJe. Importante ressaltar que de acordo com o CNJ (2020) alguns tribunais ainda utilizam softwares próprios para tramitação processual, no entanto o sistema PJe tem sido adotado pouco a pouco em grande parte dos tribunais brasileiros.

P2P \& INOVAÇÃO, Rio de Janeiro, v. 7, n. 1, p. 186-204, set. 2020/fev. 2021. 


\section{ARTIGO}

INOVAÇÃo

O PJe tem como uma de suas finalidades atender as necessidades e demandas do judiciário brasileiro, sejam os técnicos e analistas judiciários, magistrados, advogados, usuários da justiça, entre outros indivíduos envolvidos no trâmite processual. O PJe também tem como objetivo promover a redução do tempo na tramitação processual, otimização e automação de tarefas, acesso aos processos em qualquer hora e lugar, bem como qualidade e usabilidade do sistema (CONSELHO NACIONAL DE JUSTIÇA, 2010).

A Figura 1 ilustra o painel global do PJe, nos quais as funções do sistema são próprias dos analistas e técnicos judiciários.

Figura 1 - Painel Global do PJe na visão de técnicos e analistas judiciários
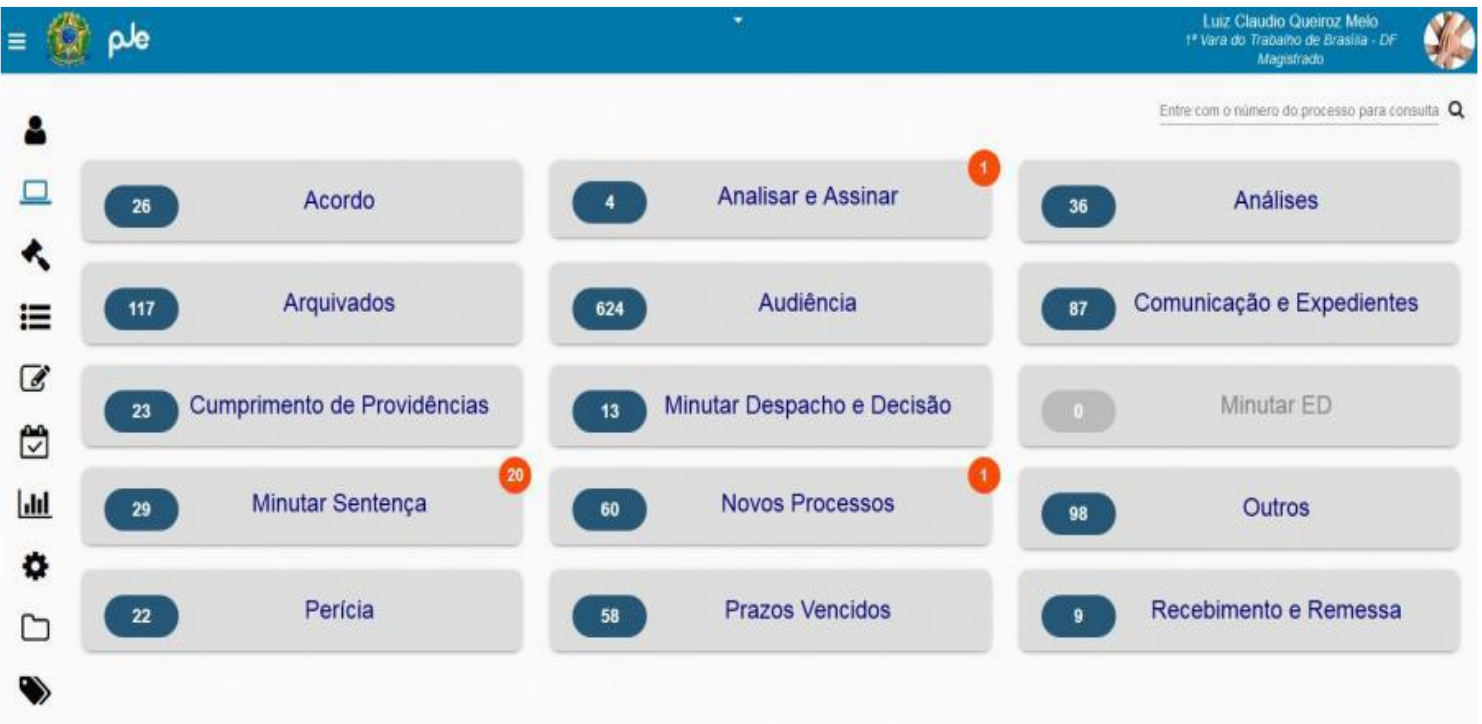

Fonte: (CONSELHO NACIONAL DA JUSTIÇA DO TRABALHO, 2019).

O painel global apresenta as funcionalidades essenciais para a abertura, tramitação e arquivamento dos processos judiciais. Além das funções do painel global, o sistema PJe em sua versão 2.0 apresenta outras funções úteis e inovadoras, a exemplo do escritório virtual, e-carta, plenário virtual, sistema nacional de videoconferência, navegador PJe e qlick view e PJe estatístico. Essas ferramentas visam ampliar e melhorar o trabalho não só dos técnicos e analistas judiciários, que lidam com a tramitação e julgamento dos processos, mas também auxiliam a gerência dos fóruns e tribunais com dados estatísticos para estabelecer metas, cumprir prazos, etc. (CONSELHO NACIONAL DE JUSTIÇA, 2016).

É plausível fazer um paralelo entre o sistema PJe, a GI e a gestão de documentos arquivísticos, afinal dispõem de etapas de inserção, classificação, busca, recuperação, uso, compartilhamento e eliminação de informações e documentos. Além do que a informatização do processo judicial, em teoria, aumenta a automação dos fluxos processuais, colaborando para uma justiça mais rápida e efetiva. Investigar de que modo acontecem as etapas da GI e se 
existem barreiras e/ou fatores facilitadores neste sistema é primordial para uma gestão e fluxo informacional que colaborem para o andamento e otimização da justiça brasileira.

\section{PROCEDIMENTOS METODOLÓGICOS}

A pesquisa se caracterizou como exploratório-descritiva, visto que apresentou revisão bibliográfica sobre Gestão da Informação e o Sistema de Processo Judicial Eletrônico e do tipo de pesquisa documental e de campo.

A pesquisa documental foi executada a partir dos estudos em manuais do sistema PJe, a exemplo das cartilhas publicadas pelo CNJ, quanto pelos sites "Wiki PJe" e "Wiki PJe do Conselho Nacional da Justiça do Trabalho (CSJT)", bem como as resoluções do CNJ e CSJT sobre adoção e requisitos do PJe.

Já na pesquisa de campo foram observados e coletadas informações, sem interferência no ambiente, com o principal objetivo de compreender as situações vivenciadas no Sistema PJe para analisá-lo na perspectiva da GI, bem como reconhecer pontos fortes que auxiliam no trâmite processual e também propor soluções para as deficiências constatadas.

A abordagem qualitativa foi obtida por entrevista semiestruturada e observação sistemática com o objetivo de analisar, descrever os fenômenos, situações e problemas vivenciados pelos usuários investigados no campo de pesquisa no TRT $13^{\mathrm{a}}$ Região. A abordagem quantitativa permitiu medir aspectos como o tempo de uso no sistema PJe, tempo de atuação dos servidores no TRT $13^{\text {a }}$ Região e cargo exercido, sendo considerado também a quantidade de respostas semelhantes ou iguais em determinadas categorias utilizadas para compreender melhor os discursos dos sujeitos.

O campo de pesquisa concentrou-se nas 13 varas do Fórum Trabalhista Maximiano Figueiredo, maior fórum do Tribunal Regional do Trabalho da $13^{\mathrm{a}}$ Região, localizado na cidade de João Pessoa/PB, e com a maior quantidade de processos trabalhistas.

Os sujeitos da pesquisa constituíram-se pelos técnicos e analistas judiciários, os quais trabalham nas 13 varas/cartórios judiciais e eram responsáveis pela abertura, tramitação, auxílio no julgamento e arquivamento dos processos.

As entrevistas foram realizadas com aqueles que se prontificaram de forma voluntária a participar da pesquisa. A identidade dos entrevistados foi mantida em sigilo, sendo codificados como E1 até E15 para manter o anonimato.

A coleta de dados ocorreu entre 14 de outubro e 08 de novembro de 2019, alcançando dos 145 técnicos e analistas judiciários do fórum, 15 funcionários, representando 10,3\% e sendo 
entrevistado pelo menos um funcionário de cada vara, garantindo a representação da visão e perspectiva de todas as varas do fórum.

A entrevista semiestruturada foi dividida em três partes: 1) perfil do servidor; 2) gestão da informação no sistema PJe e; 3) considerações sobre o sistema PJe. Por meio das respostas dos entrevistados analisaram-se os motivos, as necessidades e o dia a dia dos servidores diante do sistema PJe, em virtude de compreender satisfações e anseios dos sujeitos em relação ao sistema, com o objetivo principal de construir um discurso único e coletivo para cada resposta obtida por meio de perguntas sobre a GI no PJe.

A observação sistemática foi registrada a partir do manuseio do sistema pelos entrevistados, ocasião em que se realizaram as devidas anotações em diário de campo, junto à folha do roteiro de entrevista.

A técnica para a análise de dados foi o Discurso do Sujeito Coletivo (DSC), que tem como objetivo construir um discurso único, em primeira pessoa, os quais os sujeitos entrevistados vivenciam ou já vivenciaram determinada situação ou ambiente igual ou bastante semelhante aos demais (LEFÉVRE; LEFÉVRE, 2014). Neste caso o ambiente e situação foi o uso do sistema PJe pelos técnicos e analistas judiciários das varas trabalhistas do referido fórum.

O DSC de cada resposta foi construído a partir do grau de semelhança ou respostas iguais sobre determinada pergunta, pois,

\footnotetext{
[...] como técnica de processamento de depoimentos, consiste em reunir, em pesquisas sociais empíricas, sob a forma de discursos únicos redigidos na primeira pessoa do singular, conteúdos de depoimentos com sentidos semelhantes. Estes conteúdos de mesmo sentido, reunidos num único discurso, por estarem redigidos na primeira pessoa do singular, buscam produzir no leitor um efeito de "coletividade falando"; além disso, dão lugar a um acréscimo de densidade semântica nas representações sociais [...]. (LEFÉVRE; LEFÉVRE; MARQUES, 2009, p. 1194).
}

Dessa forma, as respostas foram categorizadas, identificando-se as expressões-chaves e as ideias centrais, construindo um discurso único baseado nas respostas iguais ou bastante semelhantes. As ideias centrais que dessoavam das demais, ou seja, não eram iguais ou semelhantes, foram excluídas do discurso do sujeito coletivo.

\section{GESTÃO DA INFORMAÇÃO NO SISTEMA PJE DO TRT 13ª REGIÃO}

Os resultados apresentados com base na entrevista semiestruturada e na observação sistemática apresentam-se em três momentos: 1. perfil do usuário do PJe; 2. etapas da GI no sistema PJe; 3. sistema PJe na visão de seus usuários. Neste artigo apresentam-se aqueles que abordam diretamente a GI. 


\section{ARTIGO}

INOVAÇÃO

No primeiro momento, sobre o perfil do usuário do PJe foi caracterizado quanto ao cargo exercido, o tempo de atuação no TRT $13^{\text {a }}$ Região e o tempo de uso do sistema PJe.

Identificou-se que $80,0 \%$ (12) dos entrevistados foram de técnicos judiciários e 20,0\% (3) de analistas judiciários. Esse resultado já era esperado, já que existem mais técnicos atuando nas varas do que analistas.

Em relação ao tempo que o servidor atuava no TRT $13^{\text {a }}$ Região, 47,0\% (7) trabalhavam entre 13 a 25 anos no tribunal, 33,0\% (5) entre 27 a 34 anos e outros 20,0\% (3) entre 1 a 8 anos. Evidenciou-se que a maioria dos entrevistados era servidor há bastante tempo, aferindo-se experiência nos trâmites processuais.

Acerca do tempo que utilizavam o sistema PJe, identificou-se que 73,0\% (11) utilizavam entre 3 a 5 anos, ressaltando que começaram a utilizar o sistema no ano de 2014, quando este foi implantando definitivamente pelo TRT $13^{\mathrm{a}}$ Região. Identificou-se também que $20,0 \%$ (3) começaram a utilizar o PJe há menos tempo, entre 6 meses a 1 ano e apenas 7,0\% (1) afirmou utilizar o sistema PJe há 8 anos, pois a vara em que trabalhava foi uma das pioneiras na Justiça do Trabalho, tal qual da justiça brasileira, a testar e empregar o sistema PJe antes de ser totalmente implantando no TRT $13^{\text {a }}$ Região.

No segundo momento, sobre a gestão da informação no sistema PJe, identificou-se as etapas de GI no TRT $13^{\mathrm{a}}$ Região, a partir da ideia central ancorada no DSC. Os resultados demonstraram como ocorre a identificação de necessidades e busca de informação, o desenvolvimento de produtos e serviços, o uso e o compartilhamento dessa informação, assim como o seu descarte a partir de quem utiliza o sistema PJe.

Acerca da etapa de identificação de necessidade de informações a ideia central do DSC foi: “O fato do processo ser eletrônico faz com que sempre seja necessário coletar informações pelo sistema PJe”. Considerando-se que a função primordial dos sistemas de informação é disponibilizar as informações fundamentais para o desenvolvimento das atividades organizacionais (AUDY; ANDRADE; CIDRAL, 2007), o sistema PJe foi representado pelo discurso coletivo como essencial para o andamento das atividades processuais, visto que é o meio de armazenamento, abertura e tramitação dos processos.

Em relação à etapa de busca de informação no sistema PJe, obteve-se o seguinte DSC: "Em geral não possuo dificuldades para buscar informações, só às vezes em determinadas pesquisas. As opções que o sistema disponibiliza e uso são: busca pelo nome das partes, pelo número do processo, pelo número do CPF ou CNPJ, pelo menu/painel de busca rápida, ferramentas e filtros específicos, pelos anexos e filtros da tela inicial, pelos menus de acordo, analisar e assinar e decisões judiciais”.

P2P \& INOVAÇÃO, Rio de Janeiro, v. 7, n. 1, p. 186-204, set. 2020/fev. 2021. 
Ressalta-se que para o sistema de recuperação da informação funcionar de forma precisa e facilitada, é necessário que se compreenda as necessidades de informação dos usuários ou demandas da instituição, métodos estatísticos, índices de precisão, revocação e metadados associados aos documentos (DINIZ; FERREIRA, 2018). Em relação a este quesito o sistema PJe apresentou, durante a observação sistemática, diversas maneiras de se buscar um processo, facilitando a recuperação do que se deseja, propiciando satisfação ao usuário, congregando com o DSC que não demonstrou dificuldade durante esta etapa.

Outro fator importante, associado à busca e recuperação da informação, tem relação com a etapa de classificação, instrumento relevante para auxiliar na recuperação das informações. Foi questionado se existia tabela de classificação processual, e o DSC foi: "Sim, existe tabela de classificação processual no sistema PJe”.

O processo de classificação de documentos é uma operação basilar da gestão de documentos arquivísticos. De acordo com Rodrigues (2013, p. 76) “[...] Significa separar, diferenciar, distinguir ou dividir um conjunto de elementos da mesma composição (órgão produtor, competências, funções, atividades) em classes, subgrupos, grupos e fundo". No caso do sistema PJe, durante a observação sistemática, verificou-se que cada processo recebia um identificador único (número processual). Essa classificação processual é fundamental para a gestão da informação e gestão de documentos, pois se torna imprescindível para a busca, recuperação e uso da informação processual.

A respeito da etapa de desenvolvimento de produtos e serviços de informação investigou-se a existência de manuais, sites e outras fontes de informação que auxiliassem em relação a dúvidas sobre o sistema PJe, construindo-se o seguinte DSC: “Sim, existem. As opções que utilizo com mais frequência são os manuais e central de chamados da informática/central de chamados eletrônico. Também há os treinamentos, a wikivt, os vídeos no youtube, como também peço orientação a outros servidores".

Ressalta-se com esse resultado que o conhecimento explícito de uma instituição está nas informações registradas. É notória a relevância de fontes que propiciem suportes de informação (ROSSEAU; COUTORE, 1998) para sanar as dúvidas dos usuários do sistema PJe. Pelo que foi observado, existem diversas opções que podem sanar dúvidas sobre as funcionalidades do sistema e assim obter satisfação do usuário neste quesito.

Na etapa de uso da informação disponíveis no sistema PJe, o DSC construído foi: “ $O$ sistema e as informações contidas nele são usadas e só servem para tramitação judicial, ou para informar o juiz e as partes do processo". O uso da informação, conforme Choo (2003) é necessário para solucionar problemas, tomar decisões, responder perguntas etc. É a etapa mais 
importante, já que é possível combinar informações, assim como obter novos conhecimentos (BEAL, 2012), para organizações e colaboradores, gerando aprendizado e crescimento pessoal e organizacional.

Vale ressaltar que o sistema PJe é exclusivo para tramitação processual, ou seja, informações referentes a outros assuntos relacionados à administração, recursos humanos, financeiros, etc. não estão disponíveis, visto que sua funcionalidade é para atividade-fim da justiça: o trâmite e julgamento processual.

A respeito da etapa de compartilhamento de informações no sistema PJe, os resultados apontaram diversas para o seguinte DSC: "Sim é possível compartilhar informações referentes aos processos judiciais pelo sistema. Compartilho principalmente por meio dos lembretes. Também existem opções como os gigs, chips, alertas, o painel com quadro de avisos." Nesta etapa sobressaíram-se a variedade de formas de compartilhamento registradas.

No entanto, apesar de demonstrar essas possibilidades de compartilhamento, um terço de respostas dos entrevistados não se inseriu neste discurso, pois, afirmaram desconhecer ou não utilizar as ferramentas do sistema PJe para compartilhar informações com outros colegas de trabalho. Isto pode ser ocasionado por desconhecimento das ferramentas ou falta da cultura do compartilhamento.

No caso da ausência da cultura do compartilhamento Barboza e Fadel (2017) recomendam estabelecer uma cultura organizacional que fomente tais práticas incentivando os colaboradores, tal qual forneça os insumos e/ou condições para tais práticas. Isto é, para que o compartilhamento de informações aconteça no sistema PJe é preciso que todos os usuários ou grande parte, esteja ciente da existência das ferramentas de compartilhamento, bem como sejam incentivados a praticar a cultura do compartilhamento no sistema.

Por fim, sobre a etapa de descarte da informação registrou-se se os técnicos e analistas judiciários do TRT $13^{\mathrm{a}}$ Região conheciam e realizavam a eliminação de dados/informações/documentos no sistema PJe, obtendo-se o seguinte DSC: “Sim, posso eliminar documentos dentro de um processo, desde que estes, por algum motivo, foram inseridos de forma errônea, ou excluídos a pedido do juiz. Precisa-se de um despacho para eliminar o documento, mas nem todos os usuários podem eliminar documentos. Pode-se eliminar os documentos, no entanto podem ser restaurados. Não posso excluir processos, apenas arquivá-los”. Identificou-se que é possível realizar a eliminação de documentos/peças dentro do processo a depender de ordem do magistrado ou se foi inserido de forma errônea, no entanto, ressalta-se que o processo não pode ser excluído do sistema.

P2P \& INOVAÇÃO, Rio de Janeiro, v. 7, n. 1, p. 186-204, set. 2020/fev. 2021. 
Levanta-se nessa etapa uma fase da gestão de documentos: a avaliação documental. Apesar de existir tabela de temporalidade que determina o tempo de guarda e destinação de cada tipo de ação judicial, a avaliação ou eliminação processual não ocorrem no sistema PJe. Isto pode ocasionar acúmulo de massa documental, podendo num futuro próximo propiciar o surgimento de barreiras informacionais, prejudicando a gestão da informação, especialmente em etapas como busca, recuperação e armazenamento no sistema. Belloto (2006) e Paes (2008) afirmam que o arquivista junto a outros profissionais da instituição deve instituir prazos de guarda aos documentos, considerando a utilidade e o valor para a instituição.

A etapa de eliminação de informações torna a GI mais eficaz no que se refere a busca, recuperação e tratamento das informações e documentos com maior excelência, já que será armazenado o que realmente é essencial para a organização (BEAL, 2012).

Por fim, sobre a GI, indagou-se se consideravam alguma etapa da GI mais importante ou que ganhasse destaque durante as atividades no sistema PJe. Obteve-se o seguinte discurso do sujeito coletivo: "Para mim todas as fases são importantes e essenciais na gestão da informação do fluxo processual. De toda forma algumas merecem destaque, como é o caso do cadastro das informações processuais, a busca, obtenção/recuperação da informação, assim como o compartilhamento de informação".

A visão dos técnicos e analistas judiciários do TRT $13^{\mathrm{a}}$ Região foi de que todas as fases da GI são importantes, pois formam um ciclo, em que se uma for prejudicada afetará todas as outras. Apesar disso, a etapa de cadastro das informações, busca, recuperação e compartilhamento foram destacados como muito importantes no processo de GI.

Para Beal (2012) a inserção de informação também pode ser chamada de captura ou registro de informação. Essa captura pode ser feita de forma interna ou externa, o modo como essa captura/inserção de informação é classificado tende a facilitar sua recuperação futura (DAVENPORT, 1998). As etapas de busca e recuperação estão interligadas a distribuição da informação. Os sistemas utilizam diversos métodos, tal qual classificam a informação de forma temática de modo a facilitar a recuperação pelos usuários (BEAL, 2012).

Sobre o compartilhamento, Nassif e Rezende (2018, p. 112) consideram que "o compartilhamento da informação toma lugar de destaque nas organizações, configurando-se em desafio na busca por compreender os fatores que o influenciam, como se estabelecem e quais resultados trazem para as organizações”. É uma etapa significativa para analisar o repasse das informações pelos setores e/ou departamentos de uma instituição, compreender o quanto isso pode influenciar no comportamento, cultura e eficiência institucional. 
No terceiro momento, obteve-se considerações sobre o sistema PJe relacionados a recursos facilitadores, barreiras no sistema e pontos para sua melhoria.

No que se refere aos fatores facilitadores para buscar informações referentes a documentos, processos ou partes processuais disponibilizados pelo sistema PJe, o DSC foi: "Sim, existem vários fatores que facilitam a busca, os mais usados são: a aba de pesquisa dentro do processo, a pesquisa por palavras, classe judicial, tipos de chips (tarefas), tarefas dos processos, subcaixa, usuários responsável e fase processual. Também uso os filtros, baixar documentos, o uso da barra de rolagem e o número do CP F. Outros que também utilizo, mas com menos frequência são: o identificador, o caderno processual e gerar pdf, movimentações do processo e o sistema SAO”.

Evidenciou-se a disponibilização de mecanismos para a busca de informações no sistema PJe e o seu pelos técnicos e analistas judiciários para facilitar essa etapa. Os fatores facilitadores disponíveis no sistema tratam-se da classificação da informação, devendo ser encarada, de acordo com McGee e Prusak (1994), por variados ângulos, pois deve ser tão variado quanto à natureza de seu material que é representado, a exemplo de filtros baseados nos metadados do documento. Assim, quanto mais categorias e filtros relacionados aos conteúdos dos documentos, mais fácil será encontrá-los, tornando-se um facilitador na GI.

Acerca das barreiras informacionais que prejudicavam a obtenção de informações e/ou interfiram na tramitação e fluxo processual, obteve-se o seguinte DSC: "O sistema PJe possui algumas barreiras que prejudicam o fluxo processual, as principais são: as constantes atualizações do sistema, lentidão no sistema quando a internet cai e a falta de comunicação entre os usuários do sistema e os desenvolvedores do sistema PJe. Existem outras barreiras como por exemplo: não permite o arquivamento do processo com pendências, ter que cumprir a determinação do despacho de uma só vez, emitir um documento por vez, a burocracia no andamento do processo, trava do sistema por falta de manutenção dos gestores da informática, e às vezes, o processo sai do fluxo de tramitação judicial”.

Foi possível registrar que muitas críticas são feitas diretamente ao setor de desenvolvimento e manutenção do sistema. Para alguns entrevistados, por exemplo, as constantes atualizações do sistema é algo negativo, pois muitas das novas ferramentas ainda não estavam desenvolvidas o suficiente para serem implantadas no sistema. Outros reclamaram que quando a velocidade da Internet cai, o sistema fica lento, visto que o PJe possui muitas informações, é um sistema complexo e "pesado" que demanda uma conexão excelente e estável com a Internet.

P2P \& INOVAÇÃO, Rio de Janeiro, v. 7, n. 1, p. 186-204, set. 2020/fev. 2021. 
Alguns fizeram críticas a uma melhor relação com os desenvolvedores do sistema, sentindo que nem sempre suas necessidades são atendidas ou que o sistema travava por falta de manutenção pelo setor de informática. Porém, apesar destas questões os tribunais, bem como o $\mathrm{CNJ}$, possuem canal de reclamações sobre o sistema e uma página na Internet relatando bugs do sistema que foram resolvidos. As demais críticas foram feitas em relação a gestão processual no que tange ao arquivamento, emissão de documentos e processos saindo do fluxo processual.

A tecnologia pode ser considerada uma barreira, em destaque os sistemas de informação que são de fato intrínsecos ao funcionamento organizacional. No entanto, quando as organizações só focam no investimento em tecnologias, mas esquecem de implementar e empregar cultura e políticas informacionais, assim como capital humano, a tecnologia pode prejudicar uma gestão eficaz dos fluxos de informação. (STAREC, 2002).

Solicitados a apontar sugestões de melhorias para a gestão da informação do sistema PJe, o resultado foi o DSC a seguir: “O sistema PJe precisa melhorar nas etapas de inclusão de informações e documentos, melhorar as buscas, ter mais opções de refinamento, melhorar a organização das pastas e subpastas (organização da informação), bem como a opção "meu painel" que trata da visualização de informações e tarefas precisa ser melhorado".

As etapas mencionadas fazem parte do processo de GI no sistema PJe: inclusão (inserção/captura), busca, opções de refinamento, organização de pastas e subpastas e visualização da informação. No que se refere a etapa de inserção de informações e documentos não foi especificado o que deve ser melhorado. Sobre a etapa de busca apelou-se para maiores opções de refinamento, sendo estas condições, na visão de Davenport (1998), essenciais para obter informação. No entanto, numa primeira avaliação, grande parte dos usuários do sistema respondeu uma diversidade de opções de filtros que auxiliam nas buscas processuais, devendo, posteriormente, investigar quais filtros a mais devem ser acrescentados.

Outro fator relatado foi sobre a organização de pastas e subpastas. Belloto (2006) afirma que este ponto se relaciona aos princípios da proveniência e ordem original, características que documentos de arquivo devem possuir. Tais pastas e subpastas onde estão incorporados os fundos, séries, subséries e itens documentais devem obedecer aos princípios arquivísticos.

Sobre a opção "meu painel”, também conhecido como painel global, não foram especificados os motivos das insatisfações ou sugerido melhorias. Supõe-se que esteja relacionado ao aspecto da Arquitetura da Informação, despertando motivação para outras pesquisas. 


\section{ARTIGO}

INOVAÇÃo

\section{CONSIDERAÇÕES FINAIS}

O estudo permitiu compreender como ocorre a gestão da informação no sistema de Processo Judicial Eletrônico (PJe) do TRT 13 ${ }^{\mathrm{a}}$ Região, adotado como solução tecnológica para gerência e tramitação de processos judiciais nos tribunais de justiça de todo Brasil.

O PJe além de um sistema de informação dados e informações, é responsável pela tramitação, gerenciamento e armazenamento dos processos, considerado documentos arquivísticos, tornando-se basilar para o trabalho dos profissionais do direito ou do cidadão usuário da justiça. Daí a relevância em analisar a GI e suas etapas.

Nesse ínterim, as etapas de busca, recuperação e compartilhamento de informações e documentos apresentaram pontos positivos, principalmente na diversidade de opções apresentadas para solucionar tais questões. O sistema, de acordo com os entrevistados, trouxe mais acessibilidade, melhoria no fluxo processual, dinamicidade das tarefas em equipe e rapidez no acesso à informação.

Apesar dos aspectos positivos relatados e observados, algumas etapas precisam de mais atenção, como é o caso do cadastro das informações e documentos, organização, armazenamento, avaliação, destinação e preservação. Mediante as entrevistas, observações e pesquisa documental sobre o sistema PJe, notou-se que apesar de os processos judiciais serem caracterizados como documentos arquivísticos e necessitarem de tratamento especial, visto as particularidades do objeto da informação, o sistema não é guiado por princípios arquivísticos, não possui integrado um sistema informatizado de gestão de documentos arquivísticos (SIGAD) e nem um repositório digital confiável (RDC-Arq) para o armazenamento seguro, pautado em critérios arquivísticos, que preservam os documentos pelo tempo necessário.

Como não há avaliação dos processos judiciais, apesar da existência de tabela de temporalidade e destinação na instituição, bem como comissão de avaliação, não há eliminação dos processos em meio digital, podendo ocasionar, num futuro próximo, o acúmulo de massa documental, dificultando outras etapas da GI e da gestão documental, como organização, busca, recuperação, uso, armazenamento e preservação.

De acordo com McGee e Prusak (1994) sobre a política de gerenciamento informacional, os desenvolvedores e equipe responsável pelo PJe encaixam-se no estilo de gerência de utopia tecnocrática, em que os gestores dão mais valor e investem nas mais novas e diversas tecnologias de hardwares e softwares, mas ignoram aspectos da gestão, preservação e políticas de informação. 
Acredita-se que isso pode ser resultado da supervalorização das tecnologias de informação e comunicação, em que basta uma grande quantidade de armazenamento e ações de backup que já parecem suficientes para garantir o acesso e uso da informação de modo adequado; quando se necessita de uma forte base de gestão e de capital humano valorado.

Diante dos resultados, convoca-se aos gestores do sistema PJe e dos tribunais da justiça brasileira, para a observância e o cumprimento dos requisitos no que tangem à gestão da informação e gestão arquivística de documentos.

Têm-se o intuito de que a gestão da informação possa ser um dos fatores que contribui de forma efetiva na tramitação e julgamento dos processos, proporcionando uma justiça célere, efetiva e que preserva a memória social e institucional por meio de seus documentos arquivísticos digitais. 


\section{REFERÊNCIAS}

AUDY, J. L. N.; Andrade, J. K.; CIDRAL, A. Fundamentos de Sistemas de Informação. Porto Alegre: Bookman, 2007.

BARBOSA, R. R. Gestão da Informação e do Conhecimento: origens, polêmicas e perspectivas. Informação \& Informação, Londrina, v. 13, n. especial, p. 1-25, 2008. Disponível em: http://www.uel.br/revistas/uel/index.php/informacao/article/view/1843/1556. Acesso em: 04 abr. 2019.

BARBOZA, E.L; FADEL, B. Fluxos de informação na gestão do conhecimento: por uma cultura de compartilhamento. In: ENCONTRO NACIONAL DE PESQUISA EM CIÊNCIA DA INFORMAÇÃO, 18., 2017. Anais [...]. Marília: UNESP, 2017. p. 1-20. Disponível em: https://www.brapci.in f.br/index.php/res/download/124991. Acesso em: 10 mar. 2020.

BEAL, A. Gestão Estratégica da Informação: Como transformar a informação e a tecnologia da informação em fatores de crescimento e de alto desempenho nas organizações. São Paulo: Atlas, 2012.

BELloto, H. B. Arquivos Permanentes: tratamento documental. 4. ed. Rio de Janeiro: Editora FGV, 2006.

BRASIL. Lei 11.419, de 19 de dezembro de 2006. Dispõe sobre a informatização do processo judicial. Brasília, DF: Presidência da República, [2016]. Disponível em: http://www.planalto.gov. br/ccivil_03/_Ato2004-2006/2006/Lei/L11419.htm. Acesso em: 04 abr. 2019.

CONSELHO NACIONAL DE JUSTIÇA. PJE - Processo Judicial Eletrônico. Brasília: Conselho Nacional de Justiça, 2010. Disponível em: https://www.conjur.com.br/dl/manualprocesso-judicial-eletronico-cnj.pdf. Acesso em: 04 abr. 2019.

CONSElHO NACIONAL DE JUSTIÇA. Caderno PJe - Processo Judicial Eletrônico.

Brasília: Conselho Nacional de Justiça, 2016. Disponível em: https://www.cjf.jus.br/observato rio/arq/caderno_pje.pdf. Acesso em: 05 abr. 2019.

CONSELHO NACIONAL DE JUSTIÇA (Brasil). Justiça em números 2020: ano base: 2019. Brasília, DF: Conselho Nacional de Justiça, 2019. Disponível em: https://www.cnj.jus.br /wp-content/uploads/2020/08/WEB-V3-Justiça-em-Números-2020-atualizado-em-25-08-2020 .pdf. Acesso em: 27 ago.2020.

CONSELHO NACIONAL DA JUSTIÇA DO TRABALHO (Brasil). Painel Global. [S. l.], 2019. Disponível em: https://pje.csjt.jus.br/manual/index.php/PJe_2.0_-_1 ${ }^{\circ} \_$Grau. Acesso em: 27 ago. 2020.

CHOO, C. W. A Organização do Conhecimento. 3. ed. São Paulo: Senac, 2003.

DAVENPORT, T. H. Ecologia da informação: porque só a tecnologia não basta para o sucesso na era da informação. São Paulo: Futura, 1998.

DINIZ, B. C; FERREIRA, D. S. Recuperação da informação no banco de dados do arquivo judicial do fórum cível de João Pessoa. RACin, João Pessoa, v. 6, n. 2, p. 1-16, jul./dez. 2018. 
Disponível em: http://racin. arquivologiauepb.com.br/edicoes/v6_n2/racin_v6_n2_artigo01.pd f. Acesso em: 10 mar. 2020.

GRÁCIO, J. C. A. Preservação Digital na Gestão da Informação: um modelo processual para as instituições de ensino superior. São Paulo: Cultura Acadêmica, 2012. Disponível em: https://repositorio.unes p. br/bitstream/handle/11449/113727/ISBN9788579833335.pdf?seque nce $=1 \&$ isAllowed=y. Acesso em: 06 abr. 2019.

LEFEVRE, F.; LEFEVRE, A. M. C. Discurso do Sujeito Coletivo: representações sociais e intervenções comunicativas. Texto \& Contexto Enfermagem, Florianópolis, v. 23, n. 2, p. 502-507, abr./jun. 2014. Disponível em: http://www.scielo.br/pdf/tce/v23n2/pt_0104-0707tce-23-02-00502.pd f. Acesso em: 06 abr. 2019.

LEFEVRE, F.; LEFEVRE, A. M. C; MARTINS, M. C. C. Discurso do Sujeito Coletivo, complexidade e auto-organização. Ciência \& Saúde Coletiva, Rio de Janeiro, v. 14, n. 4, p. 1193-1204, 2009. Disponível em: https://www.scielo.br/pdf/csc/v14n4/a20v14n4.pdf. Acesso em: 06 abr. 2019.

LIMA, E. S; DUARTE, E. N. Política integrada de gestão documental, da informação e do conhecimento para o SEBRAE/PB. In: ENCONTRO NACIONAL DE PESQUISA EM CIÊNCIA DA INFORMAÇÃO, 17., 2016. Anais [...]. Salvador: UFBA, 2016. p. 1-8. Disponível em: http://www.ufpb.br/evento/index.php/enancib2016/enancib2016/paper/view/3 798/2418. Acesso em: 10 mar. 2020.

McGEE, J.; PRUSAK, L. Gerenciamento estratégico da informação: aumente a competitividade e a eficiência de sua empresa utilizando a informação como uma ferramenta estratégica. Rio de Janeiro: Campus, 1994.

NASIF, M. E; RESENDE, W. C. Gestão da informação e do conhecimento e suas relações com segurança da informação, tecnologias da informação e compartilhamento. Ciência da Informação, Brasília, v. 45, n. 3, p. 110-118, set./dez. 2018. Disponível em: http://revista.ibic t.br/ciinf/article/view/4052/3568. Acesso em: 31 jan. 2020.

PAES, M. L. Arquivo: teoria e prática. 3. ed. Rio de Janeiro: Editora FGV, 2008.

RODRIGUES, A. C. Identificação como recurso metodológico para a gestão de documentos e acesso à informação na administração pública brasileira. Ciência da Informação, Brasília, DF, v. 42, n. 1, p. 64-80, jan. /abr. 2013. Disponível em: http://revista.ibict.br/ciinf/article/vie w/1395/1573. Acesso em: 10 mar. 2020.

ROSSEAU, J. Y; COUTURE, C. Os fundamentos da disciplina arquivística. Lisboa: Dom Quixote, 1998.

SOUZA, I. G. C. O; DUARTE, E. N. Dimensões de um modelo de gestão da informação no campo da Ciência da Informação: uma revelação da produção científica do ENANCIB. Liinc em Revista, Rio de Janeiro, v. 7, n. 1, p. 152-169, mar. 2011. Disponível em: http://revista.ibi ct.br/liinc/article/view/3276/2898.Acesso em: 07 abr. 2019.

STAREC, C. Informação e Universidade: os pecados informacionais e barreiras na comunicação da informação para tomada de decisão na universidade. DataGramaZero Revista de Ciência da Informação, Rio de Janeiro, v. 3, n. 4, p. 1-10, ago., 2002. Disponível em: https://brapci.in f.br/index.php/article/download/7486. Acesso em: 07 abr. 2019. 


\section{ARTIGO}

INOVAÇÃo

VALENTIM, M. L. P, et al. Gestão da informação utilizando o método infomapping.

Perspectivas em Ciência da Informação, Belo Horizonte, v. 13, n. 1, p. 184-198, jan./abr. 2008. Disponível em: http://portaldeperiodicos.eci.ufmg.br/index.php/pci/article/view/165/40 6. Acesso em: 18 abr. 2019.

\section{AGRADECIMENTOS}

A Coordenação de Pessoal do Ensino Superior (CAPES) pelo financiamento e apoio a esta pesquisa de mestrado. 